\title{
The Living Group Works Council Agreement as Social Innovation: Internal Crowdsourcing in the GASAG Group
}

\author{
Andreas Otte, Welf Schröter, Ingo Breite, Frank Gerth, Sylvia Laur, \\ Volker Ost, Can Sekertekin, Andreas Tabor, Marco Wedel, and \\ Hannah Ulbrich
}

\begin{abstract}
Shortly after the formal launch of the ICU project in the summer of 2017, representatives from the group works council of the GASAG group sat down with the trade union network Forum for the Social Forms of Technology, the FST, to start up an independent practical initiative to examine the topic of internal crowdsourcing to be implemented soon after. In 2018, a model works council agreement between the group works council and the management was agreed, henceforth framing the IC procedure in the GASAG group. The agreement is meant to serve as a template for the introduction of internal crowdsourcing in other companies and industries. A special feature of the agreement is the so-called 'living' group works council agreement. The following article analyses its significance and provides a translation by reproducing the agreement in its wording (This text is based on an original version in the German language that was published under the provisions of the Creative Commons at the URL: www.blog-zukunft-der-arbeit.de/betriebsraetesetzen-starken-innovationsimpuls-fuer-digitalen-aufbruch or www.blog-zukunftder-arbeit.de.).
\end{abstract}

Keywords Social innovation · Living group works council agreement · Internal crowdsourcing group works council agreement

\footnotetext{
A. Otte $\cdot$ I. Breite $\cdot$ F. Gerth $\cdot$ S. Laur $\cdot$ V. Ost $\cdot$ C. Sekertekin $\cdot$ A. Tabor GASAG AG, Groups Work Council, Berlin, Germany

W. Schröter

Forum Soziale Technikgestaltung beim DGB, Baden-Württemberg, Mössingen, Germany

e-mail: schroeter@talheimer.de

M. Wedel $(\varangle) \cdot H$. Ulbrich

Technische Universität Berlin, Institute for Vocational Education and Work Studies, Berlin, Germany

e-mail: marco.wedel@tu-berlin.de; hannah.ulbrich@tu-berlin.de
} 


\section{About the ICU Project}

The following piece was written as part of the Federal Ministry of Education and Research project 'Internal Crowdsourcing in Companies: Employee-friendly process innovations through the digital participation of employees', the ICU.

Shortly after the formal launch of the ICU project in the summer of 2017, representatives from the group works council of the GASAG group sat down with the trade union network Forum for the Social Forms of Technology, the FST, to start up an independent practical initiative to examine the topic of internal crowdsourcing to be implemented soon after. The colleagues' aim was to work out and present an own innovation concept, with them taking on the role of initiators and pioneers. This proactive concept aimed to secure employment, not by working against new digital applications but rather by actively using new IT technology. The group works council emphasized here its existing openness towards innovation and its innovation competence. The concept consisted of five action steps:

1. Consultation concerning the significance and impact of internal crowdsourcing

2. Drafting and approving a list of the main points for binding aspects concerning the design

3. Drafting and approving the design of an own draft initiative for a group works council agreement (in German 'KBV')

4. Negotiating a group works council agreement together with the group management

5. Living the ' $\mathrm{KBV}$ ' in practice

The members of the group works council and the individual company works councils were to implement steps 1-3 in 5 months. The negotiations with the group management concerning the KBV were to take 3 months.

Between September 2017 and April 2018, an unusual agreement came into being in the GASAG group which allowed the group works council and the group management to become joint pioneers in the field of internal crowdsourcing. They signed one of the first legally binding works council agreements in this area in the Federal Republic of Germany.

\section{Consulting on and Drawing up the KBV}

A participation-oriented, voluntary, company-internal innovation management process was chosen above all as a practical introduction that was accessible via an electronic platform within the GASAG group. Put more simply, a traditional voluntary proposal scheme, which to date had been organized on paper or by posting information on noticeboards, could be modernized using IC. This model was transformed into a digital platform environment. The aim here was to provide the opportunity for a working culture with 'swarm intelligence' to emerge as a way to 
source knowledge and new ideas from employees (therefore the term 'crowdsourcing') and to promote cross-departmental working.

From the perspective of trade unions and works councils, this gave rise to broader and additional aspects. The discourse between the group works council, the individual company works councils and the FST saw the voluntary, innovative sourcing of ideas as only one of the many faces of internal crowdsourcing.

One of the ways the trade unions looked at it is that we must expect, above all, that in addition to voluntary, innovative crowdsourcing, there will also be orderrelated crowdsourcing arising from the instruction right of the employer as provided for in labour law-if not immediately, then at some point in the future.

According to the works councils, voluntary IC must be designed in such a way that it takes into consideration the expected order-related and binding form of IC and, as a preventive measure, provides for codetermination (Schröter 2018b).

An approach based only on the voluntary part of IC would undervalue the potentials that IC allows for. Linking both perspectives was key for the group works council, in German 'KBR (Konzernbetriebsrat)', and FST to achieving the intended humanization strategy. This way of looking at things was the first step in the joint conceptual approach shared by the KBR and FST.

In the second action phase, an extensive list of the main points was drawn up. What points were to be developed, how were they to be developed and when? In a comprehensive dialogue, this resulted in a requirements list comprising almost 70 individual tasks. These were divided into the following sections:

- Goals for the company innovation management from the standpoint of the KBR

- Conditions for the company innovation management

- Using the electronic platforms

- Humane work design-humane work organization

- Legal framework conditions for innovation management

The first version of the list of main points was drafted by a working group made up of KBR and FST. This version was dealt with at a special session of the KBR. After adding to it, a regular KBR session approved the document as the basis for the independent draft by the KBR and FST for the initiative towards a socially innovative group works council agreement.

The third action phase of the concept was about coming up with a courageous draft for an own innovation strategy. What did the colleagues want the future of work to look like? What social standards were important? How could people organize their own learning process? The first draft of the initiative towards a group works council agreement placed the idea of a 'living KBV' at the centre of its considerations. Works council representatives and employees did not want to be pushed by the introduction of technology, wanting instead to act on their own initiative and proactively for the future of the company on an equal standing and with an active role in decision-making.

The principles behind this approach included on the one hand the realization that, at the beginning of a complex technology introduction, neither the group 
management nor the group works council knew exactly whether the goals that had been set would be successfully achieved.

What was needed was a flexible concept for change that allowed learning to take place. In addition to the idea' of 'a living KBV' came the concept of "agile cooperative change management of the digital transformation" (Schröter 2017).

The fourth action phase saw the negotiation process begin with the employee side presenting the first draft. In the negotiations, the contractual parties came closer to one another in the core task of assessing the various crowdsourcing tendencies and reached a binding understanding after 3 months of talks (see items 1.7-1.9 in 'Wording'):

With this arrangement, the group management and the group works council created a transparent and calculable entry point into designing innovative platform-based working environments (Schröter 2018a). For the KBR, it was not only important to create new innovative products and services but above all to safeguard jobs as well as forge a path towards good digital work.

Besides the points such as health and safety at work, integration and inclusion, data protection, regulating working hours and availability, etc., the two contract partners reached agreement through the KBR initiative concerning qualification steps (see 5.11. in 'Wording').

The fifth and last action phase paved the way for the new communication and work-design culture to be developed. The aim was that the contract partners come together at regular intervals in order to assess their experiences with the process and to push the further development of the 'living KBV' (see 5.13 a in 'Wording').

This was the beginning of a cooperative learning process. The 'living KBV' as social innovation and the experiences gained during its practical implementation constituted an important building block on the way towards innovative work-design competence (Otte and Schröter 2019). The plan is to pass this competence on to other sectors and companies.

The Wording of the KBV

\section{The Group Works Council Agreement (KBV) Internal Crowdsourcing in the GASAG Group ('The Living KBV')}

\subsection{Definition of Internal Crowdsourcing in the GASAG Group (IC)}

1. "As a direct result of the technological developments of the last 10 years, 'internal crowdsourcing' today represents a new form of organizing company-internal

\footnotetext{
${ }^{1}$ An idea that came from KBR Chairman Andreas Otte.
} 
cooperation and knowledge transfer processes. Through internal crowdsourcing, previously inaccessible knowledge resources, i.e. unutilized specialized and personnel know-how gained from experience by the employees is mobilized in a fast and highly efficient manner and can be sourced in interactive crowdworking in order to develop new ideas and creative solutions to problems. Proposals can then be used in a beneficial way to produce innovative, market-ready products and services, thus contributing towards an increase in the company's efficiency and profit" (Federal Ministry of Education and Research ICU project application, 2017). The GASAG group wants to use this added value from IC to its own benefit.

2. When designing IC in the GASAG group, the following IC components are relevant, among others: innovation management, employee participation and expansion of competence.

3. The goal of IC is - besides employee participation and innovation managementto develop approaches to expand employee competences by using IC. In doing so, collaborative work processes are practised in the crowd and monitored in order to evaluate existing qualification measures at GASAG on the basis of this or to realign these. The employer does not keep a record of individual competences as part of this. At the same time, the employees have the opportunity to discover their own competences and interests themselves and to articulate any further training needs or wishes and to carry out the corresponding measures.

4. From a methodological point of view, IC can be divided up into crowdstorming (making suggestions), crowdvoting, crowdsolving (putting forward concrete solution proposals) and crowdtesting (testing functionalities).

5. The topics placed on the platform to be worked through by the crowd are described as 'IC campaigns' and are named from out of the GASAG group.

6. In IC, the circle of participants is limited to the employees of the participating companies from the GASAG group.

7. External crowdsourcing (the circle of those questioned consists only of people external to the company), just like crowdworking (assigning internal work activities to an external crowd with the aim of having previously internal work activities carried out externally), is not a project goal and therefore also not part of the KBV on internal crowdsourcing in the GASAG group.

8. Order-related internal crowdsourcing (processing customer orders on the platform (also) with internal employees) is not planned at the present time as part of IC.

9. The parties agree that, before introducing crowdworking in the sense of item 1.7 or order-related crowdsourcing in the sense of item 1.8, the living group works council agreement (see item 2) will be added to accordingly or a separate group works council agreement will be concluded. 


\subsection{The 'Living Group Works Council Agreement' as Social Innovation: A Preamble}

1. The group management of the GASAG group and the group works council are treading new ground with this type of 'living group works council agreement' and allowing for new opportunities for social, technical and nontechnical innovations in the group as a whole as well as for the digital transformation of the working environments within the group.

2. The 'living group works council agreement' for platform-based internal crowdsourcing opens up new fields of action for the working culture and IC. The group management and the group works council see the agreement as a point of entry into a holistic process of organizing work with foresight, which is open going forward. Both partners undertake to carry out cooperative change management on an equal footing that is to be organized in a results-oriented manner and that is professionally and methodically agile.

3. The 'living group works council agreement' aims, on the basis of an agile, cooperative change management, to promote mutual learning throughout the group as well as the acquisition of work-design competences. For this purpose, joint assessments, joint evaluations and joint updates of the group works council agreement will take place at regular intervals as well as jointly structured evaluations of their practical implementation. Both partners work together to adapt the group works council agreement to the experience gained and the learning steps in each case.

4. The 'living group works council agreement' is to be developed in connection with the Federal Ministry of Education and Research project 'Internal Crowdsourcing in Companies' (ICU) and with its pilot phases (April 2018 until the end of February 2019) and with its best-practice phases (March 2019 until the end of November 2019).

5. The 'living group works council agreement' is at the same time based on the already existing relevant group works council agreements. Existing group works council agreements and works council agreements will not be replaced by this new additional 'living group works council agreement', and their validity, which is based on earlier decisions, will not be affected. This applies, in particular, to the group works council agreement titled 'Introduction and implementation of information and communications technology' (IuK) from 27 August 2015; for the group works council agreement titled 'Code of conduct in the GASAG companies' from 15 March 2017; or for the group works council agreement titled 'Software for multi-project management' from 8 December 2008. All signed KBVs as well as the works council agreements of the companies of the GASAG group continue to apply without restriction. 


\subsection{Goals}

The group management of the GASAG group and the group works council link the following goals to the introduction of IC:

1. Promoting employee participation, the ability to innovate and the expansion of competences.

2. Creating the prerequisites for the development of new value creation paths, new products and new services.

3. Promoting the safeguarding of local jobs and strengthening the ecologically sustainable profile of the company. The aim is, among other things, to increase the efficiency of the company as a whole through IC.

4. An IC oriented towards the values of humanization of work in line with Annex 6.8-excerpt from the KBV IuK.

5. Protecting the employees from excessive workloads is an essential aspect.

6. Influencing the corporate culture through the mutual respect people have for one another and the respectful way they treat one another.

7. The 'living group works council agreement' is a building block towards a joint future dialogue between the group management of the GASAG group and the group works council.

8. The introduction and implementation of IC does not aim to rationalize and/or cut jobs.

\subsection{Area of Application}

1. The 'living group works council agreement' applies to all employees of the GASAG group in the sense of Article 5 paragraph 1 of the Works Constitution Act if these companies participate in IC.

2. The participating companies are listed in Annex 1. If required, the Annex can be added to or amended by concluding supplementary agreements.

3. Any deviations from existing local or groupwide regulations refer exclusively to the use of IC. Existing regulations are generally not affected by it.

\subsection{Principles and Conditions of IC}

1. The participation of the employees of the GASAG group in IC is voluntary.

2. Employees face no disadvantages due to their participation or nonparticipation in IC.

3. The implementation of IC does not lead to changes in company organization.

4. The participation of the employees in IC takes places during working hours. The time spent working on platforms is working time. 
5. Specific times apply for employees who are subject to working instructions via workforce systems, or possibilities will be stored in the system pertaining to when they can take part in IC during working hours. The specific local regulations apply in each case.

6. All existing works council agreements concerning working hours as well as the Working Hours Act will be complied with for all types of utilization of IC.

7. To the extent that tasks connected to internal crowdsourcing are suitable for work from home (remote working), the employees have the chance to carry out these tasks at their home office, in line with the respectively applicable works council agreement for remote working.

8. Access to IC will be provided by the company at the workplace, mobile on a laptop (if available) and in an employee's home office. No additional IT accesses or IT workplaces will be provided for. Employees without IT access can place IT initiatives directly via the crowdmanager.

9. Measures to motivate employees to become more involved in IC must be carried out in a data-sensitive manner. Employee participation in points systems or ranking systems that are accessible to the group or to employers is exclusively voluntary. People are free to choose to use either their own name or a pseudonym.

10. Individual employees have a right of initiative, taking into consideration the definition agreed to in item 1 as part of IC, and can place company-related topics on the IC platform on their own (if necessary, via the crowdmanager if there are technical issues). This also applies for all representations of employee interests. If, in the future, it seems it would be make sense to steer the topics, the parties will consult with one another, and this regulation will be adapted accordingly.

11. The group management of the GASAG group and the group works council agree that digitization requires an expansion or improvement of the employees' competences. They therefore assess the requirements for formulating a joint qualification concept and a qualifications programme for IC at regular monitoring meetings (item 5.14) in order to make the introduction of IC easier for the employees. As part of this, the parties will check, in particular, how (a) older and (b) less technically astute employees can be encouraged and motivated to work with the IC platform. That is why, in addition to instruction in IC using eLearning, face-to-face teaching sessions will also be offered. Furthermore, all regulations concerning qualification, training and instruction as outlined in the IuK apply.

12. The rules of the group works council agreement 'Introduction and implementation of information and communications technology' (IuK) from 27 August 2015 apply for the access rights of the group works council to user data.

13. The parties agree to the following regular monitoring meetings:

(a) The parties will jointly evaluate the implementation of IC on a quarterly basis. When doing so, they will check whether there is a need to train employees, particularly older and less technically proficient employees. 
(b) The parties will carry out an annual joint assessment of the effects of IC on the group as a whole. In connection with this, data monitoring with respect to platform use will take place. The structuring and implementation of the data monitoring will be realized in binding coordination with the KBR.

(c) The parties will assess on an annual basis whether there has been an increase in mental illnesses.

\subsection{Using an Electronic IC Platform}

1. To implement IC, an online platform hosted by crowdees will be used as a white-label solution in the GASAG group. The IC platform is not generally accessible to third parties, with the exception of the administrators.

2. With respect to the internal crowdsourcing with the help of the group-internal platform, the GASAG group undertakes to handle data security and data protection in a particularly sensitive manner that goes beyond the regulations laid down in the Federal Data Protection Act. Any use data generated for the platform will only be made available to the company bodies or departmental heads and supervisors in an aggregated and anonymized form and, if requested, to the research consortium. A person-related breakdown of data does not take place. The aim of this is to strengthen the employees' right to self-determination over their personal data as well as their trust in the company and its mindful corporate culture.

3. The goal is to have an open and transparent exchange among the employees. In order to keep people's inhibitions in using IC as low as possible, the employees will have the individual right to use a pseudonym for their inputs.

4. The data traffic to and from the platform will be encoded (HTTPS).

5. In order to safeguard the employee concerns and rights worthy of protection, reference is made to the group works council agreement 'Introduction and implementation of information and communications technology' (IuK) from 27 August 2015 (cf. the quotations in the Annex).

6. The processing of voluntarily submitted user data requires a separate agreement. The processing of voluntarily submitted user data in gaming contexts requires the explicit consent of the gamer in question. Any profiles created beyond that are not permitted.

7. Following the end of the experimental and best-practice phase, the group management of the GASAG group and the group works council jointly decide what analyses or evaluations should be drawn up. Based on this, the parties agree to use the data available from the IC platform explicitly for this purpose. Data under a pseudonym may not be subsequently transformed into real names and evaluated.

8. The storing of user data is limited to a maximum of 1 year.

9. An evaluation portal will be added to the IC platform thus enabling employees of the GASAG group to assess the platform interface, the platform usability, the 
IC moderation and the quality of the communications processes in the same way as school grades are given and, if required, to make comments.

10. Individual access to the platform is provided using registered employee accounts.

11. Disclosing a real name behind a pseudonym requires the dual consent of the group works council and the group management. This is done if persons using a pseudonym insult other people or otherwise do not comply with heedful and respectful conduct or if they violate obligations to maintain secrecy arising from employment contracts or provisions from the informational unbundling. The disclosure takes place with the involvement of a KBR member.

12. The group management will work with the operator to ensure that the platform interface and its architecture meet the requirements of accessibility for the deaf, visually impaired, etc. (reading function, zoom function, etc.). On the other hand, end devices must be retrofitted accordingly if participation in IC is otherwise not possible.

\subsection{Humane Work Design: Humane Work Organization}

1. With respect to humane work design and work organization, reference is drawn to Annex 6.8-excerpt from the KBV IuK.

2. In order to protect employees, no controls of performance or conduct will take place. Online surveillance of any kind and monitoring of performance and conduct controls is not permitted. Ranking-also in connection with gamification-is not possible without the consent of the group works council. The parties do agree, however, that gamification is a useful instrument for motivating employees to use the platform.

3. IC is to be managed with a culture of mutual respect and appreciative conduct towards one another as well as in accordance with the values of inclusion and diversity.

4. In order to reinforce health and safety at work and to improve forward-looking work design and occupational safety, a risk assessment will be carried out within the group during the pilot phase in accordance with the statutory obligations. Among other things, mental stress is to be assessed. Particular attention must be paid to complexity, work concentration, independent work planning and collaboration that topics remain varied and to employee participation, which are relevant in connection with agile forms of work. After the IC introduction, risk assessments are to be carried out as required.

5. The parties agree that, if it is necessary and sensible to conclude a group works council agreement on 'Good Agile Work' in order to best exploit the advantages of agile organizational models and semiautonomous forms of work in the sense of a humanization of work, such a KBV will be negotiated. This agreement will, in particular, set upper limits for agile work areas and the rights of the employees 
concerned. If the group management and the KBR recognize the need for such a $\mathrm{KBV}$, they will seek to conclude said agreement in due time.

\subsection{Legal Framework Conditions for IC}

1. The group management of the GASAG group and the group works council undertake to conclude an agreement on a bonus regulation for successfully accepted innovation suggestions after the end of the experimental and bestpractice phase and based on an evaluation of the motivation steps to increase the number of employees participating. Here, earlier experiences gained from idea management should be taken into consideration. This regulation will be agreed as a supplement to this KBV.

2. Innovation ideas that are brought into IC by company employees of the GASAG group become the legal property of the group. Providers of ideas have the right to an appropriate remuneration. The details are to be agreed in the regulation to be met according to item 8.1 .

3. The contents of IC are subject to confidentiality.

4. In the case of unintended misconduct concerning patents or rights of use by the employee, the company is liable.

5. The laws of the Federal Republic of Germany apply to all matters pertaining to copyright, rights of use or patent issues that are communicated concerning IC.

\subsection{Entering into Force, Termination and Continued Application}

1. This works council agreement enters into force upon signing. After being signed, the document is public.

2. During the pilot phase (April 2018 to the end of March 2019) and the bestpractice phase (April 2019 to the end of December 2019), this works council agreement can be terminated in writing under compliance with the statutory period of notice. It continues to be valid, to the extent that the regulations are subject to enforceable codetermination.

3. Following that, if IC is to continue on a long-term basis, the group works council agreement can be terminated by each of the contractual parties with a period of notice of 3 months to the end of the calendar year. Termination requires the written form.

4. The group works council agreement continues to be valid to the extent that the regulations are subject to enforceable codetermination.

5. If this group works council agreement is terminated, irrespective by what party, the parties undertake to start negotiations within 3 months of receiving the 
termination concerning a regulation to replace this group works council agreement. This does not apply if the employer does not want to continue IC.

signed GASAG signed KBR

\section{Annex 1 Participating Group Companies}

$[\ldots]$

\section{Annex 2 Excerpts from the Group Works Council Agreement 'Introduction and Implementation of Information and Communications Technology' (IuK) from}

\section{August 2015}

\section{Excerpt Concerning 5.11}

\section{Qualifying the Users, Training Courses and Instruction}

- The qualifications necessary for using the applications, as well as follow-up and advanced training courses for the employees are to be carried out at the cost of the employer. The respective contracting party is responsible for the execution of such measures. The project management or division can be assigned to do this. The divisions are generally responsible for follow-up training courses.

- The time at which qualification measures are carried out is to be chosen, if possible, so that these have been completed by the time the new system is launched and working with the new system can begin as soon as possible following completion of the qualification. Qualification measures generally take place during working hours or are set off against working hours.

- The training and further training measures must enable the employee to carry out their work using the IuK technologies to be introduced.

- In line with the Works Constitution Act, the responsible works council representatives will be involved in any training concept.

- Participation in training measures is to be confirmed by issuing a certificate or confirmation of participation.

- Training or further training measures are assessed immediately following completion of the measure in order to take into consideration possible improvements. 


\section{Excerpt Concerning 6.5}

\section{Main Features of the Application of the IuK}

1. Decisions concerning the introduction of IuK technologies require an analysis of the work organization, a needs analysis and a tasks analysis as well as a feasibility study. These initial planning steps must also include a concept for personnel development and analysis of the qualification needs.

2. In IuK projects, the affected employees must be involved at an early stage. This requires IuK projects to be transparent; the employees also need to be qualified for the project work and, if necessary, released from their normal work duties.

3. The following principles are to be agreed as a framework for orientation and as a guideline both for the introduction of new systems and the further development of existing ones:

Humane work design:

- Humane work design covers the three areas technology, work organization and employee qualification. When change happens in one of the three areas, the consequences for the other areas must be taken into consideration at the same time and with the same priority, and the corresponding measures for their design must be taken and/or taken into consideration in planning for the future.

Holism:

- The work tasks must be designed holistically. They include planning, steering, executing and monitoring activities. The work tasks must be organized in such a way that the employees concentrate on the scope they have to make decisions and take action in line with the responsibility and work tasks assigned to them. When working with computer monitors, the work content should be such that working on the monitors is alternated with other work.

\section{Protection from Controls of Performance or Conduct}

1. Personal data pertaining to conduct and performance are only evaluated as part of the intended purpose of the employment relationship and to fulfil the legal, collective-agreement-related or other contractually agreed duties (e.g. violation against group directives, guidelines or organizational guidelines) and in each individual case only with the prior consent of the works council and with the involvement of the responsible data protection officer. The regulations concerning the collection, processing and use as well as correction, deletion and blocking of data in the employment relationship pursuant to the Federal Data Protection Act (BDSG) - in particular sections 32 and 35-must be observed. In the case of abuse proceedings (fraud), the following prerequisites apply and must basically justify such proceedings: 
- Concrete suspicion against a specific employee that a crime has been committed.

- Actual indications that justify the suspicion.

- An obligation to document these indications.

- The control measures must be reasonable.

This assessment also requires the prior consent of the works council.

2. Pseudonyms or usernames may be saved and displayed in application programmes in order to identify a responsible, competent or contactable person in individual cases and to comply with legal regulations.

The protection of personal data by external service providers as part of the contracted-out processing of data is carried out in accordance with the provisions of the German Data Protection Act and the DSHB.

Personnel measures based on information obtained in violation of this agreement are invalid and must be reversed.

\section{References}

Otte A, Schröter W (2019) Zusammenarbeit mit Ingo Breite, Frank Gerth, Sylvia Laur, Volker Ost, Can Sekertekin, Andreas Tabor: Lebende Konzernbetriebsvereinbarung als soziale Innovation. Internes Crowdsourcing in der GASAG-Gruppe. Bedeutung - Bewertung - Wortlaut. In: Schröter W (ed) Der mitbestimmte Algorithmus. Gestaltungskompetenz für den Wandel der Arbeit. Talheimer Sammlung kritisches Wissen, vol 85. Technologien, Mössingen, pp 185-212

Schröter W (2017) Selbstbestimmung zwischen "nachholender Digitalisierung" und "autonomen Software-Systemen". Wenn Betriebsräte "vorausschauende Arbeitsgestaltung" erproben. In: Schröter W (ed) Autonomie des Menschen - Autonomie der Systeme. Humanisierungspotenziale und Grenzen moderner Technologien. Sammlung kritisches Wissen, vol 71. Technologien, Mössingen, pp 187-256

Schröter W (2018a) Identität in der Virtualität. Arbeit als Identitätsarbeit. In: Beutin H, Beutin W, Bleicher-Nagelsmann H (eds) "Reich der Notwendigkeit - Reich der Freiheit". Arbeitswelten in und Literatur und Kunst. Talheimer Sammlung kritisches Wissen, vol 80. Talheimer, Mössingen, pp 257-267

Schröter W (2018b) Plädoyer für einen Perspektivwechsel im gewerkschaftlichen Gestaltungsdiskurs. WSI-Mitteilungen 71(3):247-248

\footnotetext{
Andreas Otte is Chairman of the group works council of GASAG AG. Welf Schröter is head of the personnel network 'Forum Soziale Technikgestaltung' (in German 'FST') at DGB BadenWürttemberg and acts as a partner in the Federal Ministry of Education and Research project 'Internes Crowdsourcing in Unternehmen: Arbeitnehmergerechte Prozessinnovationen durch digitale Beteiligung von Mitarbeiter/innen' (Internal Crowdsourcing in Companies: Employeefriendly process innovations through the digital participation of employees; in German 'ICU'). Andreas Tabor is Deputy Chairman of the group works council. Ingo Breite, Frank Gerth, Volker Ost, Can Sekertekin and Andreas Tabor as works council representatives, together with the Representative of Employees with Disabilities Sylvia Laur, as well as Andreas Otte and Welf Schröter, formed the negotiating delegation for the employee side. The ICU project is run by the Institute of Vocational Education and Work Studies (IBBA) at the Technical University Berlin. Overall management is in the hands of sociologist (Dipl. Soz.).
} 
Dr. Marco Wedel is a Political Scientist (Dipl.rer.pol., Dr. phil.) and Senior Researcher at the Department of Vocational Education, Technology and Participation at the Technical University of Berlin. In addition to study visits to Boston, Constance and Berlin, he has worked in the Energy Sector (BASF) and in Science Management (Falling Walls Foundation), among other things. His current research activities focus on the topics future of work, entrepreneurship, digitalization and media competence. His long-term research focuses on European integration, democratic competence and sustainable development. Marco Wedel is co-editor of the science journal 'InnovationThe European Journal of Social Science Research'.

Hannah Ulbrich holds a Degree in Sociology (Dipl. Soz.-Bielefeld/Berlin) and is a Senior Researcher at the Department of Vocational Education, Technology and Participation at the Technical University of Berlin. There, she is the project leader of the BMBF- and ESF-funded research project 'ICU-Internal Crowdsourcing in Companies'. In addition to her work as a project manager, she is a scholarship holder of the Berlin Professional School of Economics and Law where she is currently completing a part-time MBA programme. Her research focus is on entrepreneurship and innovation, new work and agility and digital transformation and leadership.

Open Access This chapter is licensed under the terms of the Creative Commons Attribution 4.0 International License (http://creativecommons.org/licenses/by/4.0/), which permits use, sharing, adaptation, distribution and reproduction in any medium or format, as long as you give appropriate credit to the original author(s) and the source, provide a link to the Creative Commons licence and indicate if changes were made.

The images or other third party material in this chapter are included in the chapter's Creative Commons licence, unless indicated otherwise in a credit line to the material. If material is not included in the chapter's Creative Commons licence and your intended use is not permitted by statutory regulation or exceeds the permitted use, you will need to obtain permission directly from the copyright holder.

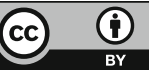

